SECTION 21. Pedagogy. Psychology. Innovations in the field of education.

\author{
Bazylbaeva Anastasiya Aleksandrovna \\ primary school teacher, psychologist \\ secondary school № 43, Taraz, Kazakhstan
}

Kurmasheva Zhuldyz Satiyevna mathematics teacher school № 37 named after Suleimenov I., Taraz, Kazakhstan

\title{
INNOVATIONS IN PROFILE EDUCATION AND THEIR IMPLEMENTATION IN THE NAZARBAEV INTELLECTUAL OR OTHER SCHOOLS OF TARAZ.
}

The article considers the problem of choice of school in connection with the development of innovative technologies in teaching.

Key words: school, training, profile orientation.

\section{ИННОВАЦИИ В ПРОФИЛЬНОМ ОБУЧЕНИИ И ИХ ВНЕДРЕНИЕ В НАЗАРБАЕВ ИНТЕЛЕКТУАЛЬНЫХ И ДРУГИХ ШКОЛАХ ТАРАЗА.}

В статье рассматривается проблема выбора иколь в связи с развитием инновачионных технологий в обучении.

Ключевые слова: икола, обучение, профильная направленность.

Развитие системы образования в школах становится особенно актуальным в связи с внедрением новых школ [1], имеющих строго профильную направленность. Так например, в Таразе - Назарбаев интелектуальная школа имеет физико-математическое направление профильного обучения.

Выбор школы становится для родителей главным залогом всестороннего развития ребенка. Ни для кого не секрет, что чем образованнее человек, чем более глубоки и разносторонне его знания, тем больше у него шансов добиться в жизни успеха[2]. Поэтому каждый родитель осознает важность выбора «правильной» школы для своего ребенка, отправляющегося в 1 класс. На что нужно обратить внимание при выборе школы в Таразе, чтобы ближайшие 11 лет Ваш ребенок получал только лучшие знания?

Здесь важно сочетание огромного количества факторов. Но главными приоритетами в любом случае должны оставаться: 
- репутация школы,

- оснащение школы,

- организация учебного процесса,

- наличие кружков и секций.

Как известно - все государственные, специализированные и частные начальные и общеобразовательные школы Тараза обязаны проводить обучение школьников по государственной программе. То есть государством разрабатываются определенные учебные планы для государственных и частных начальных и общеобразовательных школ, для специализированных школ, т.е. так называемых школ с уклоном[2].

Но все же каждая школа имеет возможность и пытается разнообразить этот процесс и предлагает, наряду с государственной программой обучения, другие. Вот именно эти методики профильного обучения и могут сыграть решающую роль в более качественой подготовке ученика [3].

По мнению Карягиной Е.А. - активизация профильной деятельности по математике призвана не только возбуждать и поддерживать у учеников интерес к предмету, но и желание заниматься ею дополнительно, как под руководством учителя во внеурочное время, так и при целенаправленной самостоятельной познавательной деятельности по приобретению новых знаний. Одной из форм внеурочной работы по предмету является неделя математики[4].

Проведение таких профильных недель в наших школах должно стать традицией. Рассмотрим проведение подобной профильной недели.

- Неделя математики будет проходить в каждом учебном году.

- В подготовке участвуют все учителя математики и инициативная группа из учеников, проявляющих повышенный интерес к математике.

- Примерно за 2 недели продумывается план проведения мероприятий, степень заинтересованности учеников школы.

- При составлении плана мероприятий учитываются возрастные и психологические особенности развития учеников.

- В течение недели проводятся математические КВНы, конкурсы, викторины, вечера.

- В завершении недели проводится школьная математическая олимпиада.

- Неделя заканчивается общешкольным математическим вечером, на котором подводятся итоги, награждаются победители, выпускается стендовый доклад.

По нашему мнению необходимо также и активное внедрение элективных курсов, не только в старших классах, но и в среднем звене. 
Ведь известно, что неотъемлемой частью профильного обучения является организация и проведение элективных курсов по математике и другим предметам.

Элективные курсы - это обязательные для посещения курсы по выбору, целями которых является развитие, дополнение, углубление содержания базового и профильного курсов математики, удовлетворение познавательных интересов школьников, развитие различных сторон математического мышления, воспитание мировоззрения и личностных качеств средствами углублённого изучения математики. При разработке содержания, выборе форм и методов работы с учащимися различных профилей на занятиях элективного курса должны быть учтены психологопедагогические особенности, типы мышления, склонности и способности школьников [3]. Проведённый в ходе исследования анализ учебнометодической литературы, изучение опыта работы учителей математики, опытное преподавание показали, что проблема разработки и организации элективных курсов по математике до конца не решена - нет достаточной ясности в отборе содержания для различных профилей, мал опыт проведения таких занятий молодыми преподавателями, недостаточно учебно-методической литературы на казахском языке.

Актуальность профильного обучения [3]

\begin{tabular}{|l|l|l|}
\hline & $\begin{array}{l}\text { Возраст } \\
\text { школьников }\end{array}$ & Результаты социологического исследования \\
\hline 1. & $6-7$ классы & $\begin{array}{l}\text { 35-40\% школьников определились с выбором } \\
\text { профиля дальнейшего обучения }\end{array}$ \\
\hline 2. & 8 класс & $\begin{array}{l}\text { школьники точно знают, что они пойдут в ПТУ, } \\
\text { техникумы, колледжи или будут поступать в ВУ3 }\end{array}$ \\
\hline 3. & 9 класс & $\begin{array}{l}\text { 70-75\% школьников точно определились с выбором } \\
\text { профиля дальнейшего обучения }\end{array}$ \\
\hline 4. & $9-11$ классы & $\begin{array}{l}\text { больше 70\% школьников отдают предпочтение тому, } \\
\text { чтобы знать основы главных предметов, а углублённо } \\
\text { знать только те, которые выбираются, чтобы в них } \\
\text { специализироваться }\end{array}$ \\
\hline
\end{tabular}

В университетах сформировалось устойчивое мнение о необходимости дополнительной специализированной подготовки старшеклассников для прохождения вступительного ЕНТ, и дальнейшего образования в ВУЗе.

Анализ зарубежного опыта показывает, что общее образование на старшей и средней ступени во всех развитых странах является профильным [5]. 
Одним из вариантов профильного обучения математике может стать предложенный [6] набор элективных курсов для каждого из трёх профилей.

\section{Физико-математический профиль:}

1. «Функции и графики»: исследование функций методами математического анализа; касательная к графику функции; асимптоты; представление о выпуклости и вогнутости графиков; исследование функции с помощью второй производной; использование касательной и свойств функции при решении уравнений и неравенств.

2. «Элементы математической логики»: высказывания; операции над высказываниями; отрицание; законы логики; кванторы; неравенства; тождества; равносильность; математические теоремы, их виды; логическая структура теорем; необходимы и достаточные условия.

3. «Задачи с параметром»: задачи, приводящие к исследованию корней квадратного трёхчлена; задачи о расположении корней квадратного трёхчлена; некоторые уравнения и неравенства, решение которых основано на использовании свойств квадратного трёхчлена; уравнения и неравенства, решение которых основано на использовании монотонности и экстремальных свойств входящих в них функций; нестандартные по формулировке задачи, связанные с уравнениями и неравенствами: нахождение числа корней, определение целочисленных корней и т.д.; уравнения и неравенства с параметрами, аналитические и графические методы их решения.

\section{Гуманитарный профиль:}

1. «Замечательные теоремы и факты геометрии»: теорема Пифагора, различные способы её доказательства и её роль в геометрии; обобщения теоремы Пифагора; теоремы Чевы и Менелая; Теоремы Паппа и Дезарга; теорема Паскаля; теорема Птолемея.

2. «Великие русские учёные-математики»: Софья Ковалевская, Пафнутий Львович Чебышев и др.

3. «Элементы математической логики»: высказывания; операции над высказываниями; отрицание; законы логики; кванторы; неравенства; тождества; равносильность; математические теоремы, их виды; логическая структура теорем; необходимы и достаточные условия.

\section{Социально-экономический профиль:}


1. «Элементы комбинаторики, теории вероятностей и статистики»: бесформульная комбинаторика; основные понятия комбинаторики: перестановки, размещения, сочетания; задачи, решаемые с использованием формул комбинаторики; бином Ньютона; треугольник Паскаля; случайное событие; виды событий; алгебра событий; вероятность события; теоремы о вероятности объединения и пересечения событий; схема испытаний Бернулли; статистические характеристики: среднее арифметическое, размах, мода, медиана; статистические исследования: сбор и группировка статистических данных, наглядное представление статистической информации.

2. «Задачи с экономическим содержанием»: вычисление ставок процента в банке, определение начальных вкладов и наращенных сумм, исчисление налогов с населения и предприятий; простые и сложные проценты, расчёты банка с вкладчиками и заёмщика с банком, дисконтирование функций в экономике, их графики; средние и предельные издержки, оптимальные размеры производства, эластичность, нахождение наибольшего выпуска при заданных бюджетных ограничениях и наименьших бюджетных затрат при заданном выпуске; излишки потребителей и продавцов, исчисление налогов, последствия дотаций; использование показательных и логарифмических функции в банковской и налоговой системах, в рыночных конструкциях.

3. «Элементы математической логики»: высказывания; операции над высказываниями; отрицание; законы логики; кванторы; неравенства; тождества; равносильность; математические теоремы, их виды; логическая структура теорем; необходимы и достаточные условия [7].

Для различных профилей темы и содержание элективных курсов могут быть различны, а могут и совпадать.

С другой стороны развитие высокоинтелектуальных школ предложенных Н.А.Назарбаевым в своем послании, не может быть основанно только на этой концепции, а методика должна охватывать намного более широкую область.

Так принято считать, что математика - царица наук, и любая наука становится по-настоящему наукой, только когда она начинает использовать математику. Весь процесс обучения сейчас, а в особенности математики, должен проводиться на персональных компьютерах. Вычисления в столбик и расчерчивание таблиц - вчерашний день. Существуют различные специализированные программные пакеты для статистического анализа, компьютерной алгебры, визуализации расчетов, моделирования физических процессов такие как SPSS или «Statistics for Windows», Stadia, Maple, MathCad, Delphi, Axum, Comsol и ряд других. 
Однако большинство программных пакетов написаны на английском языке и требуют серьезных математических знаний.

Проблемы обучения в Вузе, для большинства школьников, связаны именно $\mathrm{c}$ недостаточной школьной базой математических знаний. Выпускники специализированных классов и школ физикоматематического профиля предпочитают учиться на факультетах, изучающих точные науки. Первокурсники в Вузах Тараза более 75\% показывают очень низкие знания даже элементарной математики (данные статистики ТарГУ). Исходя из этих соображений, необходимо пересмотреть весь процесс математической подготовки школьников. И включить в школах наряду с упомянутыми курсами - «Компьютерный анализ функций», «Математические пакеты компьютерной алгебры», «Комбинаторика и элементы теории вероятностей для экономических исследований». Задания для индивидуальной работы школьников необходимо разрабатывать вместе с психологами.

\section{Литература.}

1. Назарбаев Интеллектуальная школа в Таразе. [Электронный ресурс]. URL: http://ak-ordasy.kz/ru/projects/197/ (дата обращения: 27.04.2013).

2. Государственные и частные начальные и общеобразовательные школы в Tаразе. [Электронный pecypc]. URL: http://pr-cy.kz/vse-dlyadetej/gosudarstvennye-i-chastnye-nachalnye-i-obshheobrazovatelnye-shkolyv-taraze/ (дата обращения: 28.04.2013).

3. Элективные курсы по математике в профильной школе, Киров, 2008. -59 стр. [Электронный ресурс]. URL:

http://www.coolreferat.com/Элективные_курсы_по_математике_в_профил ьной_школе (дата обращения: 28.04.2013).

4. Карягина Е.A., Неделя математики в школе. [Электронный ресурc]. URL: http://festival.1september.ru/articles/104362/ (дата обращения: 28.04.2013).

5. Болотов, В.А. Перспективы перехода школы на профильное обучение [Текст] / В.А. Болотов. // Воспитание школьников. - 2004. - №1. - с. 2-8.

6. Концепция модернизации российского образования на период до 2010 года [Текст] // Нормативные документы в образовании. - 2003. - №2. c. $2-21$.

7. Элективные курсы по математике [Текст]: учебно-методические рекомендации. / М.В. Крутихина, 3.В. Шилова. - Киров, ВятГГУ. - 2006. - c. -40 